\title{
Dothiorella omnivora isolated from grapevine with trunk disease symptoms in Hungary
}

Article in European Journal of Plant Pathology · August 2017

DOI: $10.1007 / \mathrm{s} 10658-017-1323-5$

CITATIONS

0

5 authors, including:

\section{Kalman Zoltan Vaczy}

Eszterházy Károly University

10 PUBLICATIONS 68 CITATIONS

SEE PROFILE

Levente Kiss

University of Southern Queensland

130 PUBLICATIONS 1,458 CITATIONS

SEE PROFILE
READS

38
Gábor M Kovács

Eötvös Loránd University

99 PUBLICATIONS 2,073 CITATIONS

SEE PROFILE

Some of the authors of this publication are also working on these related projects: 


\title{
Dothiorella omnivora isolated from grapevine with trunk disease symptoms in Hungary
}

\author{
Kálmán Zoltán Váczy • Márk Z. Németh • \\ Anett Csikós • Gábor M. Kovács • Levente Kiss
}

(C) Koninklijke Nederlandse Planteziektenkundige Vereniging 2017

\begin{abstract}
During a four-year project conducted to identify fungal species associated with grapevine trunk diseases (GTDs) in Hungarian vineyards, two nonsporulating strains isolated from vines exhibiting typical GTD symptoms were identified as Dothiorella omnivora based on their nrDNA ITS and EF1- $\alpha$ sequences. Conidial production of these strains was induced on pine needle medium where production of spermatia has also been observed. Pathogenicity tests confirmed their virulence on potted vines. Dothiorella omnivora is a recently described species of the Botryosphaeriaceae, known to infect hazelnut, ash, walnut, and other woody hosts. This is the first European record of D. omniovora from vines exhibiting GTD symptoms.
\end{abstract}

\section{K. Z. Váczy}

Food and Wine Research Institute, Eszterházy Károly University, Leányka utca 6, Eger H-3300, Hungary

\section{Z. Németh • G. M. Kovács • L. Kiss $(\bowtie)$}

Plant Protection Institute, Centre for Agricultural Research, Hungarian Academy of Sciences (MTA-ATK), P.O. Box 102, Budapest H-1525, Hungary

e-mail: Levente.Kiss@usq.edu.au

\section{A. Csikós}

Georgikon Faculty, Institute of Plant Protection, University of Pannonia, Deák Ferenc u. 57, Keszthely H-8360, Hungary

\section{G. M. Kovács}

Institute of Biology, Department of Plant Anatomy, Eötvös Loránd University, Pázmány Péter sétány 1/C, Budapest H-1117, Hungary

L. Kiss

Centre for Crop Health, University of Southern Queensland,

Toowoomba, QLD 4350, Australia
Keywords Botryosphaeriaceae - Grapevine trunk diseases (GTDs) · Dothiorella spp.

Grapevine trunk diseases (GTDs) represent a complex, economically important, and hard to manage plant pathological problem in viticulture worldwide (Bertsch et al. 2013). Numerous xylem-inhabiting and other phytopathogenic fungi have already been detected to be associated with GTDs; among these, some species of the Botryosphaeriaceae seem to be the most important pathogens involved in this trunk disease complex (van Niekerk et al. 2006; Úrbez-Torres et al. 2010, 2012; Pitt et al. 2010; Carlucci et al. 2015; Wunderlich et al. 2015).

GTDs caused by Botryosphaeriaceae species have long been detected in Hungarian vineyards. One of these diseases, Black Dead-Arm, a wood necrosis of trunks and arms of infected vines, associated with foliar symptoms, was first described in the Hungarian Tokaj wine region (Lehoczky 1974). However, apart from a recent study focusing on GTDs caused by Diplodia seriata (Kovács et al. 2017), and the first detection of Seimatosporium vitis associated with GTDs in the country (Váczy 2017), little research has been done on this disease complex during the past two decades in Hungary. Therefore, to better understand, and manage, GTDs in Hungary, in 2013 we started a project to identify fungal species associated with trunk diseases in Hungarian vineyards. A large number of isolates were obtained from symptomatic trunk samples, and their tentative identifications were done based on colony morphology, conidiogenesis, and conidial morphology in the case of sporulating cultures, and routine sequencing 
and analysis of the internal transcribed spacer (ITS) region of the nuclear ribosomal DNA (nrDNA) for non-sporulating cultures. Two strains belonging to this second group exhibited nrDNA ITS sequences identical to those of Dothiorella omnivora in this preliminary identification process. As D. omnivora, a recently described species, was reported as a pathogen of hazelnut, walnut, ash, and other, not closely related woody species, and only a single strain, isolated in Australia, was known from grapevine worldwide (Linaldeddu et al. 2016), we carried out a more detailed study of these two Hungarian strains. The objectives of this work were to: (i) verify the identity of these strains based on a phylogenetic analysis of their ITS and partial translation elongation factor 1-alpha gene (EF1- $\alpha$ ) sequences; (ii) induce their sporulation in culture and verify their identify based on sporulation characteristics, as well; and (iii) confirm the pathogenicity of these strains on grapevine.

To isolate fungal strains, woody samples were collected at random from vines exhibiting typical GTD symptoms in different Hungarian vineyards. Samples were washed, and bark tissues were removed before being transversally sectioned to produce $0.5-1 \mathrm{~cm}$ thick disks from parts exhibiting both healthy and necrotic tissues. Discs were surface sterilized in $1 \%$ chloramine B solution for $5 \mathrm{~min}$, rinsed in sterile distilled water and dried in a laminar flow cabinet. Small woody pieces were removed with a sterile needle from the margins of necrotic and healthy plant tissues, placed on potato dextrose agar (PDA) and incubated at room temperature. The emerging individual colonies were transferred separately to new plates with PDA, to obtain pure cultures of the fungal strains coming from woody tissues. When this was achieved, DNA was extracted and the nrDNA ITS region was amplified and sequenced with the primer pair ITS1F/ITS4 in non-sporulating cultures, as described in Szentiványi et al. (2005). In two strains, M7 and M38, ITS sequences were identical to those of D. omnivora (e.g., GenBank accession no. KF729083). Both strains were isolated from approximately 25 years old grapevine trunks in Eger, Hungary, in 2013: M7 from cv. Pinot Gris, and M38 from cv. Csókaszőlő. Their ITS sequences were deposited in NCBI GenBank (accession numbers: KY672850 and KY672851) and strain M38 at CBS-KNAW Culture Collection (Westerdijk Fungal Biodiversity Institute, Netherlands) under accession number CBS142586.

In addition to ITS sequences, up to 250-280 bp fragments of the translation elongation factor 1-alpha gene (EF1- $\alpha)$, spanned by primers EF446f and EF1035r (Inderbitzin et al. 2010), are also available for several strains of D. omnivora in GenBank (e.g., KF575053). We determined an $>850$ bp long fragment of the EF1- $\alpha$ gene in strains M7 and M38 using primers EF1-526F (Rehner 2001) and EF1-1567R (Rehner and Buckley 2005). PCR conditions were as described by Rehner and Buckley (2005), with one modification: we decreased the initial annealing temperature to $62{ }^{\circ} \mathrm{C}$. Each PCR amplification was carried out in parallel in three tubes under identical conditions, and the three PCR products were mixed before direct sequencing, to minimize the effects of DNA polymerase errors, as described in Kovács et al. (2008, 2011). Sequences were manually assembled from chromatograms using the Staden Package (Staden et al. 2000). The EF1- $\alpha$ sequences obtained in this way were deposited in GenBank under accession numbers KY681037 and KY681038, and included the fragment spanned by primers EF446f/ EF1035r, reported by Linaldeddu et al. (2016) and Zlatkovic et al. (2016) for some D. omnivora strains.

To carry out a comprehensive analysis of the phylogenetic relationships of strains M7 and M38 within the Botryosphaeriaceae, the ITS sequences and the EF1- $\alpha$ gene fragments amplifiable with primers EF446f/ EF1035r were retrieved for a total of 22 closely related taxa from GenBank (Table 1). Sequences of these two loci were aligned with online MAFFT version 7 (Katoh and Standley 2013) using E-INS-i and FFT-NS-i algorithms, respectively. As indel motifs have the potential to improve branch supports in phylogenies (Nagy et al. 2012), these were coded in both loci as binary characters (Löytynoja and Goldman 2008) with FastGap 1.2 (Borchsenius 2007). Resulting indel matrices were added to the ITS-EF1- $\alpha$ dataset and used in our phylogenetic analyses. The alignment was deposited at TreeBASE (submission ID 21196).

Maximum likelihood (ML) analysis was carried out using raxmlGUI 1.5 (Silvestro and Michalak 2012; Stamatakis 2014) with four partitions set corresponding to ITS (480 characters), EF1- $\alpha$ (273 characters) and their indels (11 and 16 characters, respectively). Thus, the final four-partition dataset for phylogenetic analyses consisted of 24 sequences with 780 characters. A nucleotide substitution model GTR + G was used with ML estimation of base frequencies in ITS and EF1- $\alpha$ dataset and BINGAMMA in the indel datasets. There were 10 runs of ML and the supports of the branches were calculated from 1000 bootstrap replicates. 


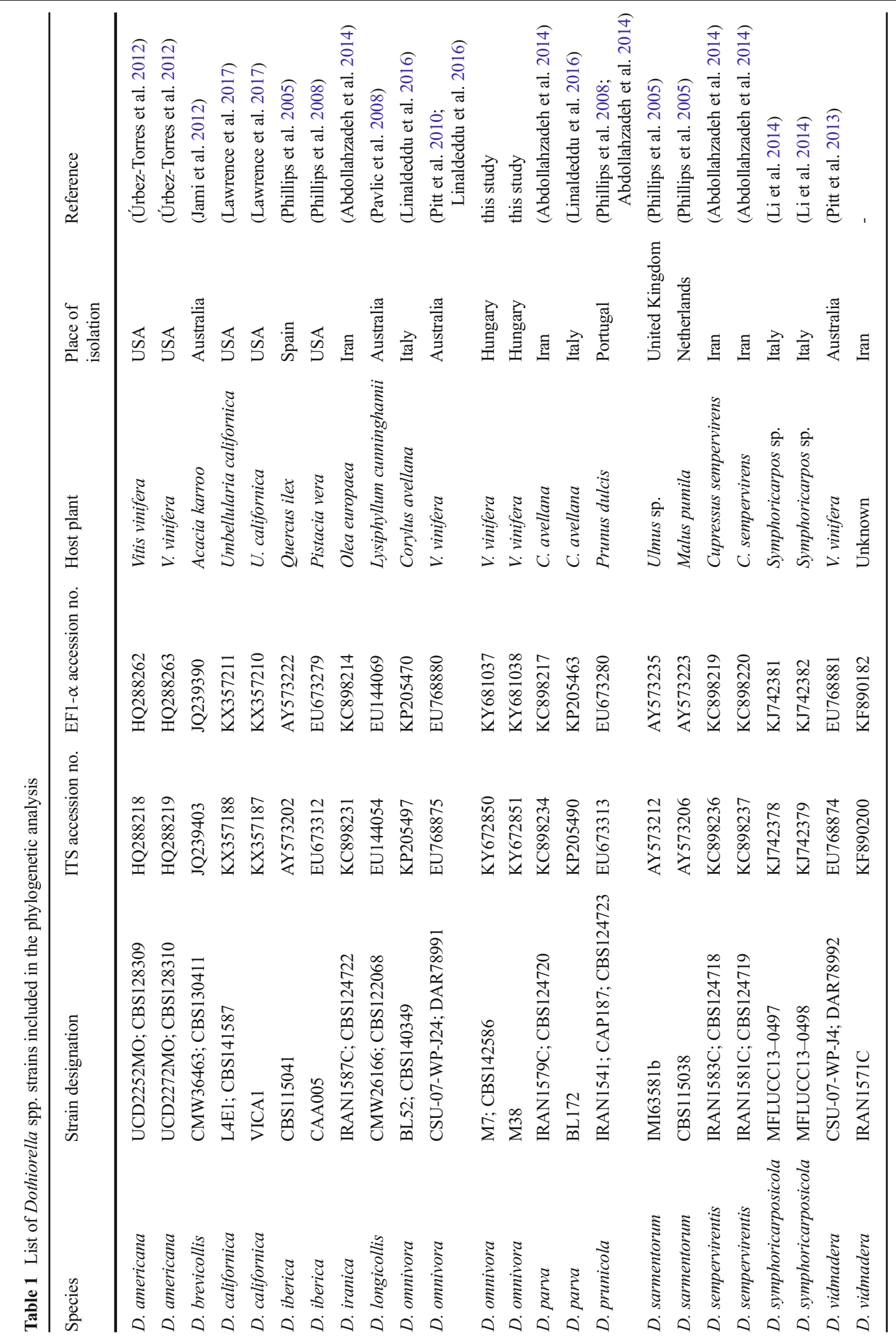


Bayesian (MCMC) analysis was performed with MrBayes 3.1.2 (Huelsenbeck and Ronquist 2001), with partitions set as above and parameters estimated separately for the partitions. Specified models were GTR + $G$ for DNA sequence data and two parameter Markov $(\mathrm{Mk}, \mathrm{k}=2)$ for indels. Two Markov chains were run for $10,000,000$ generations and every 1000 th tree was sampled. The fist 4000 trees were discarded (burn in). Trees resulting from analyses were visualized in MEGA7 (Kumar et al. 2016) and TreeGraph 2.13.0 (Stöver and Müller 2010).

To induce sporulation in strains M7 and M38, mycelial disks of their cultures maintained on PDA were transferred to water agar plates, each containing a pine needle autoclaved three times, and the cultures were monitored every day for the presence of pycnidia. The pine needle medium has long been known to induce sporulation in some ascomycetous fungi, and in particular in the Botryosphaeriaceae (Smith et al. 1996; Crous et al. 2006).

The pathogenicity of strains M7 and M38 was verified using approx. 5-month old shoots of 1.5 year old, asymptomatic potted vines, cv. Kékfrankos, produced in a greenhouse, as described by Váczy (2017). Shoots were surface sterilized with $70 \%$ alcohol and wounded to the pith with a sterile transfer needle. Each plant had one wounded shoot. Mycelial discs, $4 \mathrm{~mm}$ diameter, cut from 2-week old, non-sporulating cultures were sealed with Parafilm on the wounded surface of the shoots and plants were kept in a greenhouse at room temperature with natural daylight. Control shoots received the same treatment with sterile PDA discs. Three plants were inoculated with each strain and two others served as controls. The test was carried out twice. Shoots were examined three weeks following inoculations. The pathogen was re-isolated from the symptomatic tissues and the ITS sequence was determined in the newly obtained isolates.

The phylogenetic analysis confirmed the identity of strains M7 and M38. Fig. 1 shows the ML tree; the Bayesian analysis resulted in the same grouping of taxa. The two Hungarian strains grouped together with strain CBS140349, the ex-holotype of D. omnivora (Linaldeddu et al. 2016), isolated from hazelnut, and

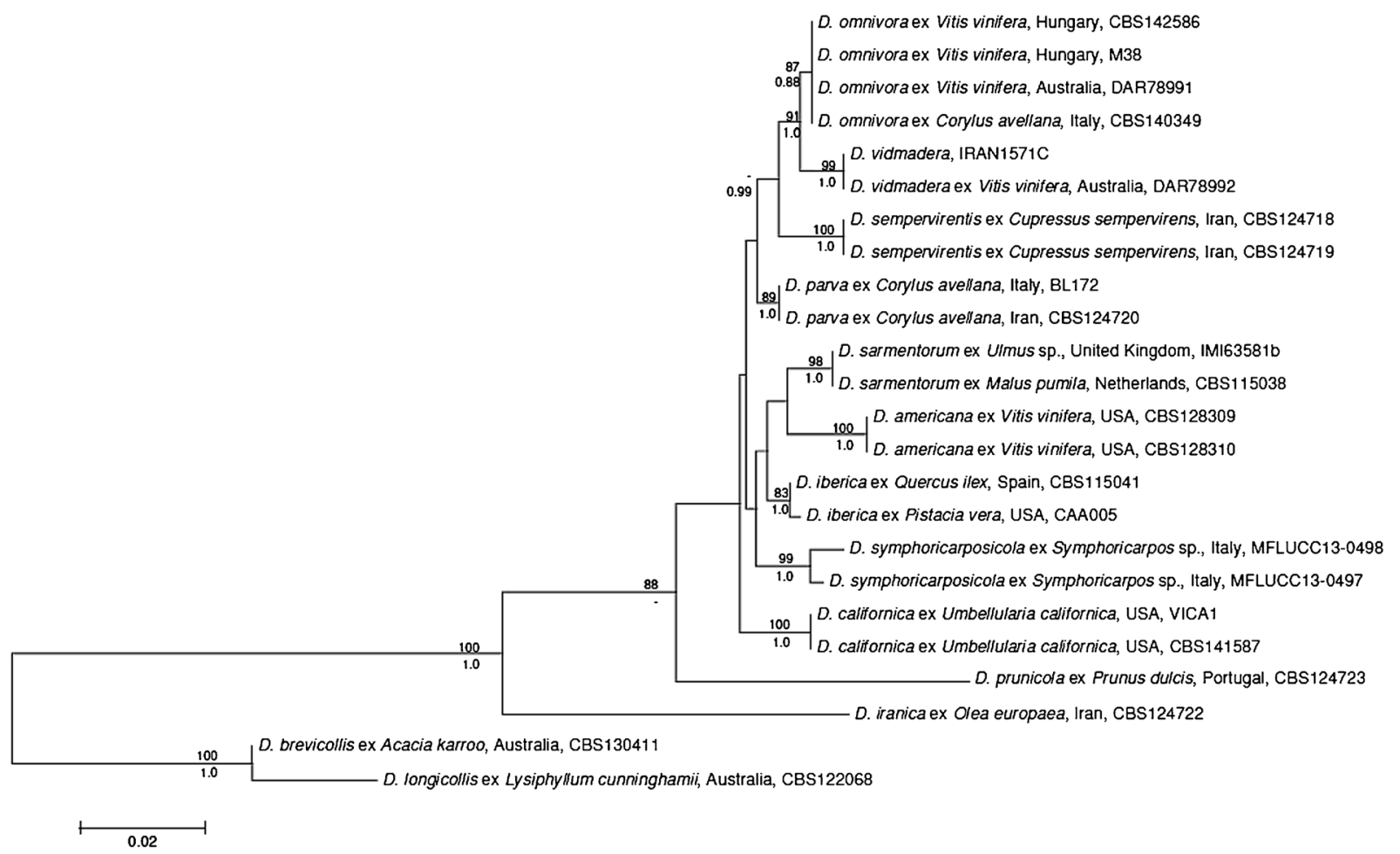

Fig. 1 The best Maximum Likelihood (ML) tree resulted from the phylogenetic analysis. The outgroup was selected and the tree was rooted based on Linaldeddu et al. (2016). Bootstrap values calculated from 1000 replicates in ML analysis are written as percentages above the branches (no values shown below 70\%) and posterior probabilities below the branches (no values shown below 0.8). Bar indicates 0.02 expected changes per site per branch 

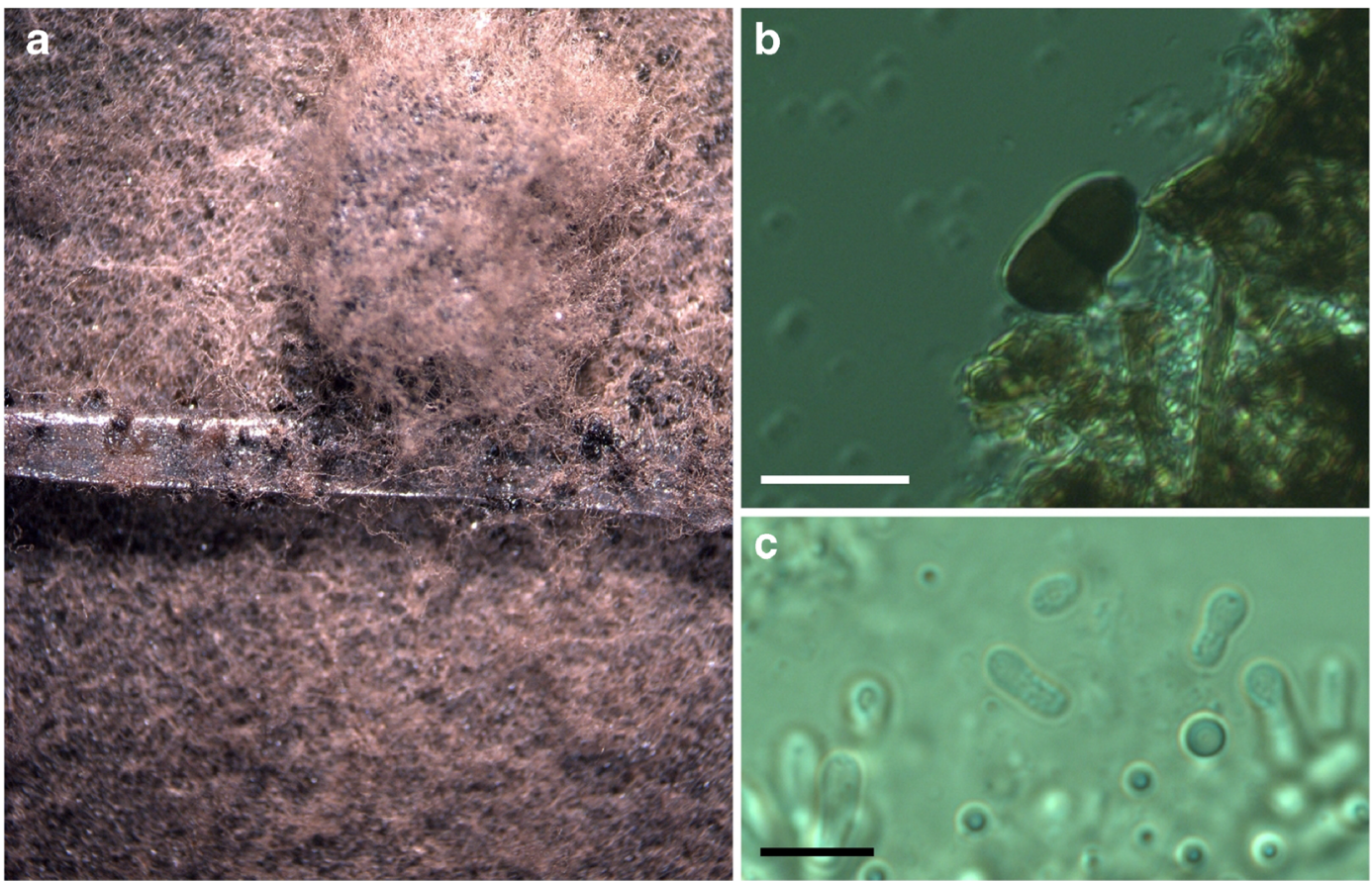

Fig. 2 Induction of sporulation in Dothiorella omnivora strain CBS142586 (M7). a Production of pycnidia on pine needle medium. b A conidium, bar: $25 \mu \mathrm{m}$. c Spermatia produced in a fruiting body, bar: $5 \mu \mathrm{m}$

strain DAR78991, isolated from grapevine in Australia (Pitt et al. 2010) and later identified as D. omnivora (Linaldeddu et al. 2016).

Conidial morphology supported the identification of strains M7 and M38. In both strains, pycnidia appeared within 10 to 14 days on the surface of pine needles (Fig. 2a), and contained brownish, ellipsoid-ovoid, 1-septate conidia, measuring 20-26 × 8-10 $\mu \mathrm{m}$ (Fig. 2b). Later on, in 1-month old colonies kept on pine needle agar, spermatia were also detected in the fruiting bodies (Fig. $2 \mathrm{c})$. This is the first report of the production of spermatia in D. omnivora strains.

Both strains infected grapevine, cv. Kékfrankos, during pathogenicity tests. Three weeks after inoculations, each shoot inoculated with fungal cultures exhibited a 2 to $3.5 \mathrm{~cm}$ long lesion which extended both upward and downward from the point of inoculation (Fig. 3). No symptoms were observed on controls. The pathogen was re-isolated and the ITS sequences, determined in three isolates, were identical to those determined earlier.

In addition to those ITS and EF1- $\alpha$ sequences available for $D$. omnivora in GenBank which were identical to the sequences determined in strains M7 and M38, there are also some other ITS and EF1- $\alpha$ entries deposited for D. omnivora in GenBank which differ in a few nucleotides from those determined in this study. Also, BLAST searches using the ITS sequences of strains M7 and M38, or their EF1- $\alpha$ fragments spanned by primers EF446f/EF1035r, revealed up to 96-99\% similar, or identical sequences in GenBank under the names Dothiorella spp., Diplodia sp., and, most notably, as Botryosphaeria iberica. This is not surprising because $D$. omnivora is closely related to B. iberica and a number of other species of the Botryosphaeriaceae (Linaldeddu et al. 2016). When BLAST searches were done with the entire, 862 and 885 bp long EF1- $\alpha$ sequences determined in strains M7 and M38, respectively, these revealed similar EF1- $\alpha$ regions in different members of the Botryosphaeriaceae, but not in D. omnivora, because EF1- $\alpha$ sequences longer than those determined by Linaldeddu et al. (2016) and Zlatkovic et al. (2016) are not available for $D$. omnivora strains to date. In spite of its limitations, different fragments of EF1- $\alpha$ sequences have long been used for species identifications in the Botryosphaeriaceae (Slippers et al. 2017; ÚrbezTorres et al. 2017), and the $>850$ bp long EF1- $\alpha$ sequences determined in this work for $D$. omnivora may be useful in future detailed phylogenetic studies.

To our knowledge, this is the first European record of D. omnivora from grapevine, and associated 


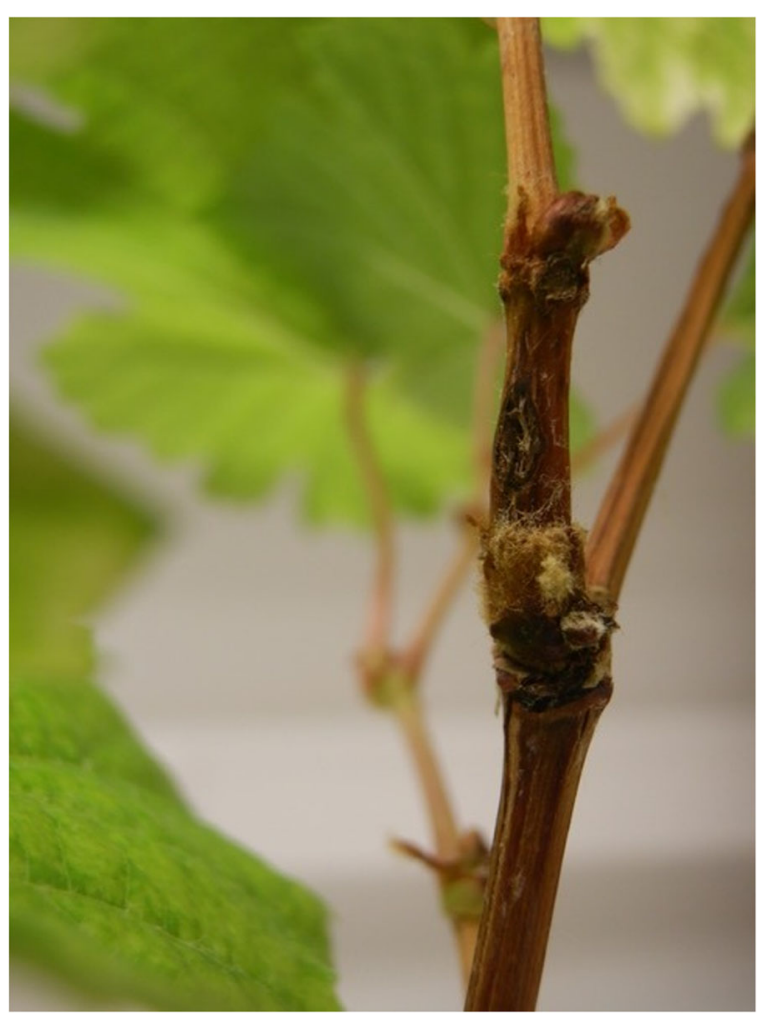

Fig. 3 Infection of a vine shoot, cv. Kékfrankos, with a mycelial disc of strain CBS142586 (M7), three weeks after inoculations (after removal of the mycelial disc from the wound)

with GTDs. Most known European D. omnivora strains came from hazelnut, ash, walnut, Chamaecyparis lawsoniana, Ostrya carpinifolia and Thuja occidentalis (Linaldeddu et al. 2016). To date, a single D. omnivora strain has been isolated from grapevine, in Australia (Pitt et al. 2010, 2014), where the role of the Botryosphaeriaceae in grapevine diseases has long been extensively studied (Qiu et al. 2015; Wunderlich et al. 2015). Other, extensive surveys of GTD pathogens (e.g., Úrbez-Torres et al. 2010, 2012; Carlucci et al. 2015) have not identified this species in vineyards. This may suggest that $D$. omnivora is not a major grapevine pathogen. On the other hand, Gramaje et al. (2016) have recently highlighted that a number of GTD pathogens are also causing disease in almond, pistachio, walnut, and other tree crop plantations; therefore, the same fungi may have an impact on the productivity of vineyards, nut orchards, and other tree crop plantations, as well. Although still little studied, D. omnivora may be one of these species which occur in a wide range of woody crops.
Acknowledgements This work was funded by the Széchenyi 2020 programme, the European Regional Development Fund and the Hungarian Government (GINOP-2.3.2-15-2016-00061). COST Action FA1303 and EU H2020 project no. 652601 have also supported this study.

Compliance with ethical standards This research and its presentation in this manuscript followed the rules of good scientific practice as described on the journal website.

Conflict of interest The authors declare no conflict of interest.

Human and animals studies This research did not involve human participants and animals.

\section{References}

Abdollahzadeh, J., Javadi, A., Zare, R., \& Phillips, A. J. L. (2014). A phylogenetic study of Dothiorella and Spencermartinsia species associated with woody plants in Iran, New Zealand, Portugal and Spain. Persoonia: Molecular Phylogeny and Evolution of Fungi, 32, 1.

Bertsch, C., Ramírez-Suero, M., Magnin-Robert, M., Larignon, P., Chong, J., Abou-Mansour, E., Spagnolo, A., Clément, C., \& Fontaine, F. (2013). Grapevine trunk diseases: complex and still poorly understood. Plant Pathology, 62, 243-265.

Borchsenius, F. (2007). FastGap 1.0.8. Software distributed by the authors at Available: http://192.38.46.42/aubot/fb/FastGap home.htm).

Carlucci, A., Cibelli, F., Lops, F., \& Raimondo, M. L. (2015). Characterization of Botryosphaeriaceae species as causal agents of trunk diseases on grapevines. Plant Disease, 99, $1678-1688$

Crous, P., Slippers, B., Wingfield, M., Rheeder, J., Marasas, W., Philips, A., Alves, A., Burgess, T., Barber, P., \& Groenewald, J. (2006). Phylogenetic lineages in the Botryosphaeriaceae. Studies in Mycology, 55, 235-253.

Gramaje, D., Baumgartner, K., Halleen, F., Mostert, L., Sosnowski, M. R., Úrbez-Torres, J. R., \& Armengol, J. (2016). Fungal trunk diseases: a problem beyond grapevines? Plant Pathology, 65, 355-356.

Huelsenbeck, J. P., \& Ronquist, F. (2001). MrBayes: Bayesian inference of phylogenetic trees. Bioinformatics, 17, 754-755.

Inderbitzin, P., Bostock, R. M., Trouillas, F. P., \& Michailides, T. J. (2010). A six-locus phylogeny reveals high species diversity in Botryosphaeriaceae from California almond. Mycologia, 102, 1350-1368.

Jami, F., Slippers, B., Wingfield, M. J., \& Gryzenhout, M. (2012). Five new species of the Botryosphaeriaceae from Acacia karroo in South Africa. Cryptogamie Mycologie, 33, 245266.

Katoh, K., \& Standley, D. M. (2013). MAFFT multiple sequence alignment software version 7: improvements in performance and usability. Molecular Biology and Evolution, 30, 772780 . 
Kovács, G. M., Trappe, J. M., Alsheikh, A. M., Bóka, K., \& Elliott, T. F. (2008). Imaia, a new truffle genus to accommodate Terfezia gigantea. Mycologia, 100, 930-939.

Kovács, G. M., Jankovics, T., \& Kiss, L. (2011). Variation in the nrDNA ITS sequences of some powdery mildew species: do routine molecular identification procedures hide valuable information? European Journal of Plant Pathology, 131, $135-141$.

Kovács, C., Balling, P., Bihari, Z., Nagy, A., \& Sándor, E. (2017). Incidence of grapevine trunk diseases is influenced by soil, topology and vineyard age, but not by Diplodia seriata infection rate in the Tokaj wine region, Hungary. Phytoparasitica, 45, 21-32.

Kumar, S., Stecher, G., \& Tamura, K. (2016). MEGA7: Molecular evolutionary genetics analysis version 7.0 for bigger datasets. Molecular Biology and Evolution, 33, 1870-1874. msw054.

Lawrence, D. P., Hand, F. P., Gubler, W. D., \& Trouillas, F. P. (2017). Botryosphaeriaceae species associated with dieback and canker disease of bay laurel in northern California with the description of Dothiorella californica sp. nov. Fungal Biology, 121, 347-360.

Lehoczky, J. (1974). Black dead-arm disease of grapevine caused by Botryosphaeria stevensii infection. Acta Physiologica Academiae Scientiarum Hungaricae, 9, 319-327.

Li, W., Liu, J., Bhat, D. J., Camporesi, E., Xu, J., \& Hyde, K. D. (2014). Introducing the novel species, Dothiorella symphoricarposicola, from snowberry in Italy. Cryptogamie Mycologie, 35, 257-270.

Linaldeddu, B. T., Deidda, A., Scanu, B., Franceschini, A., Alves, A., Abdollahzadeh, J., \& Phillips, A. J. L. (2016). Phylogeny, morphology and pathogenicity of Botryosphaeriaceae, Diatrypaceae and Gnomoniaceae associated with branch diseases of hazelnut in Sardinia (Italy). European Journal of Plant Pathology, 146, 259-279.

Löytynoja, A., \& Goldman, N. (2008). An algorithm for progressive multiple alignment of sequences with insertions. Proceedings of the National Academy of Sciences of the USA, 102, 10557-10562.

Nagy, L. G., Kocsubé, S., Csanádi, Z., Kovács, G. M., Petkovits, T., Vágvölgyi, C., \& Papp, T. (2012). Re-mind the gap! Insertion - deletion data reveal neglected phylogenetic potential of the nuclear ribosomal internal transcribed spacer (ITS) of fungi. PloS One, 7(11), e49794. https://doi. org/10.1371/journal.pone.0049794.

van Niekerk, J. M., Fourie, P. H., Halleen, F., \& Crous, P. W. (2006). Botryosphaeria spp. as grapevine trunk disease pathogens. Phytopathologia Mediterranea, 45, 43-54.

Pavlic, D., Wingfield, M. J., Barber, P., Slippers, B., Hardy, G. E. S. J., \& Burgess, T. I. (2008). Seven new species of the Botryosphaeriaceae from baobab and other native trees in Western Australia. Mycologia, 100, 851-866.

Phillips, A. J. L., Alves, A., Correia, A., \& Luque, J. (2005). Two new species of Botryosphaeria with brown, 1-septate ascospores and Dothiorella anamorphs. Mycologia, 97, 513-529.

Phillips, A. J. L., Alves, A., Pennycook, S. R., Johnston, P. R., Ramaley, A., Akulov, A., Crous, P. W. (2008). Resolving the phylogenetic and taxonomic status of dark-spored teleomorph genera in the Botryosphaeriaceae. Persoonia Molecular Phylogeny and Evolution of Fungi, 21(1), 29-55.

Pitt, W. M., Huang, R., Steel, C. C., \& Savocchia, S. (2010). Identification, distribution and current taxonomy of
Botryosphaeriaceae species associated with grapevine decline in New South Wales and South Australia. Australian Journal of Grape and Wine Research, 16, 258-271.

Pitt, W. M., Úrbez-Torres, J. R., \& Trouillas, F. P. (2013). Dothiorella vidmadera, a novel species from grapevines in Australia and notes on Spencermartinsia. Fungal Diversity, 61, 209-219.

Pitt, W. M., Úrbez-Torres, J. R., \& Trouillas, F. P. (2014). Dothiorella and Spencermartinsia, new species and records from grapevines in Australia. Australasian Plant Pathology, $44,43-56$.

Qiu, Y., Steel, C. C., Ash, G. J., \& Savocchia, S. (2015). Hierarchical genetic variation of Botryosphaeriaceae species associated with decline and dieback of grapevine in southeastern Australia. Australian Journal of Grape and Wine Research, 21, 458-467.

Rehner, S. (2001). Primers for Elongation Factor 1-a (EF1-a). Available at: http://www.aftol.org/pdfs/EF1 primer.pdf. Assembling the Fungal Tree of Life, Corvallis.

Rehner, S. A., \& Buckley, E. (2005). A Beauveria phylogeny inferred from nuclear ITS and EF1- $\alpha$ sequences: evidence for cryptic diversification and links to Cordyceps teleomorphs. Mycologia, 97, 84-98.

Silvestro, D., \& Michalak, I. (2012). raxmlGUI: A graphical frontend for RAxML. Organisms, Diversity and Evolution, 12, 335-337.

Slippers, B., Crous, P. W., Jami, F., Groenewald, J. Z., \& Wingfield, M. J. (2017). Diversity in the Botryosphaeriales: looking back, looking forward. Fungal Biology, 121, 307321.

Smith, H., Wingfield, M. J., Coutinho, T. A., \& Crous, P. W. (1996). Sphaeropsis sapinea and Botryosphaeria dothidea endophytic in Pinus spp. and Eucalyptus spp. in South Africa. South African Journal of Botany, 62, 86-88.

Staden, R., Beal, K. F., \& Bonfield, J. K. (2000). The Staden package, 1998. Methods in Molecular Biology, 132, 115130.

Stamatakis, A. (2014). RAxML version 8: a tool for phylogenetic analysis and post-analysis of large phylogenies. Bioinformatics, 30, 1312-1313.

Stöver, B. C., \& Müller, K. F. (2010). TreeGraph 2: combining and visualizing evidence from different phylogenetic analyses. BMC Bioinformatics, 11, 7 .

Szentiványi, O., Kiss, L., Russell, J. C., Kovács, G. M., Varga, K., Jankovics, T., Lesemann, S., Xu, X. M., \& Jeffries, P. (2005). Ampelomyces mycoparasites from apple powdery mildew identified as a distinct group based on single-stranded conformation polymorphism analysis of the rDNA ITS region. Mycological Research, 109, 429-438.

Úrbez-Torres, J. R., Battany, M., Bettiga, L. J., Gispert, C., McGourty, G., Roncoroni, J., Smith, R. J., Verdegaal, P., \& Gubler, W. D. (2010). Botryosphaeriaceae species sporetrapping studies in California vineyards. Plant Disease, 94, 717-724.

Úrbez-Torres, J. R., Peduto, F., Striegler, R. K., Urrea-Romero, K. E., Rupe, J. C., Cartwright, R. D., \& Gubler, W. D. (2012). Characterization of fungal pathogens associated with grapevine trunk diseases in Arkansas and Missouri. Fungal Diversity, 52, 169-189.

Úrbez-Torres, J. R., Hand, F. P., Trouillas, F. P., \& Gubler, W. D. (2017). Pomegranate dieback caused by Lasiodiplodia 
gilanensis in California. European Journal of Plant Pathology, 148, 223-228.

Váczy, K. Z. (2017). First report of Seimatosporium vitis associated with grapevine trunk disease symptoms in Hungary. Plant Disease, 101, 253.

Wunderlich, N., Ash, G. J., Steel, C. C., Raman, H., \& Savocchia, S. (2015). Association of Botryosphaeriaceae grapevine trunk disease fungi with the reproductive structures of Vitis vinifera. VITIS-Journal of Grapevine Research, 50, 89-96.

Zlatkovic, M., Keca, N., Wingfield, M. J., Jami, F., \& Slippers, B. (2016). Botryosphaeriaceae associated with the die-back of ornamental trees in the Western Balkans. Antonie Van Leeuwenhoek, 109, 543-564. 